\section{CLINICAL LEGAL MEDICINE - COMMUNITY HEALTH OUTREACH, RESULTS OF A FOLLOW-UP PAN-EUROPEAN SURVEY}

N Gage-Lindner*, A Heinemann, D Seifert, J Siemer, K Pschel Correspondence: Hesse Department of Labour, Family and Health, Dostojewskistr. 4 Wiesbaden 65197, Germany

\subsection{6/ip.2010.029215.914}

In a follow-up 2007/2008 to the first pan-European survey of legal medicine contributions to community health responses to gender violence, child and elderly abuse in 2003/2004, we investigated strategies legal medicine and forensic nursing are pursuing to provide violence victims low-threshold access to evaluation and documentation of injuries.

Methodology A standardised written questionnaire submitted to $n=227$ medicolegal experts in 33 European countries. Country comparisons of several dimensions were conducted.

Results In the 94 responses (41.4\% response rate), $92 \%$ reported services in clinical legal medicine, $43 \%$ initiated in 1990 or later. $19 \%$ examine more than 1000 patients, $16 \%$ more than 100 children p.a. 94\% investigate sexualised violence, $48 \%$ have paediatric-gynaecological expertise, $16 \%$ evaluate psychological abuse. Multi-professionality is increasing, teams include law, social work, clinical psyche and psychiatry, dentistry, gynaecology, paediatrics, forensic nursing. Forensic nursing is a growing expertise with $12 \%$ reported from the original $15 \mathrm{EU}$ member states and Switzerland. Medicolegal competence centres in Germany provide highest rate of service outside office hours. Legal frameworks vary from inclusion in health/social welfare system to exclusive liaison with law enforcement and justice. Medicolegal evaluation is explicitly required or recommended in several countries.

Conclusions Diversity in legal and financial parameters contributes to vast structural differences. Medicolegal approaches strengthen community health responses to violence. Mixing roles - medicolegal expert and health provider -creates ethical challenges. Funding remains a challenge. International knowhow transfer and networking remain a priority. 